\title{
Metaplastic breast carcinomas are basal-like tumours
}

\author{
J S Reis-Filho, ${ }^{1,2}$ F Milanezi, ${ }^{2,3}$ D Steele, ${ }^{1}$ K Savage,,${ }^{1}$ P T Simpson, ${ }^{4} \mathrm{~J}$ M Nesland,,${ }^{5}$ E M Pereira, ${ }^{6}$ \\ S R Lakhani ${ }^{4} \&$ F C Schmitt ${ }^{3,7}$ \\ ${ }^{1}$ The Breakthrough Toby Robins Breast Cancer Research Centre, Institute of Cancer Research, London, UK, ${ }^{2}$ Life and Health \\ Sciences Research Institute (ICVS), School of Health Sciences, University of Minho, Braga and IPATIMUP_Institute of \\ Molecular Pathology and Immunology, University of Porto, Porto, Portugal, ${ }^{4}$ Molecular \& Cellular Pathology, Mayne \\ Medical School, University of Queensland, Queensland Institute of Medical Research and Royal Brisbane and Women's \\ Hospital, Brisbane, Australia, ${ }^{5}$ The Norwegian Radium Hospital, University of Oslo, Montebello, Norway, ${ }^{6}$ Laboratório \\ Salomão E Zoppi, São Paulo, Brazil, and ${ }^{7}$ Porto Medical Faculty, University of Porto, Porto, Portugal
}

Date of submission 22 September 2005

Accepted for publication 15 November 2005

Reis-Filho J S, Milanezi F, Steele D, Savage K, Simpson P T, Nesland J M, Pereira E M, Lakhani S R \& Schmitt F C (2006) Histopathology 49, 10-21

\section{Metaplastic breast carcinomas are basal-like tumours}

Aims: Recently, an immunohistochemical panel comprising antibodies against HER2, oestrogen receptor (ER), epidermal growth factor receptor (EGFR) and cytokeratin (CK) 5/6 was reported to identify basal-like breast carcinomas, as defined by cDNA microarrays. Our aim was to analyse a series of metaplastic breast carcinomas (MBCs) using this panel plus two other basal markers (CK14 and p63) and progesterone receptor (PR), to define how frequently $\mathrm{MBCs}$ show a basal-like immunophenotype.

Methods and results: Sixty-five cases were retrieved from the pathology archives of the authors' institutions and reviewed by three of the authors. Immunohistochemistry with antibodies for HER2, ER, EGFR, CK5/6,
CK14 and p63 was performed according to standard methods. All but six cases (91\%) showed the typical immunoprofile of basal-like tumours (ER- and HER2-, EGFR+ and/or CK5/6+). When CK14 and p63 were added to the panel, two additional cases could be classified as basal-like. The majority of MBCs lacked PR, except 4/19 (21\%) carcinomas with squamous metaplasia.

Conclusions: Our results demonstrate that $\mathrm{MBCs}$ show a basal-like phenotype, regardless of the type of metaplastic elements. Moreover, as these neoplasms frequently overexpress EGFR (57\%), patients with MBC may benefit from treatment with anti-EGFR drugs.

Keywords: carcinosarcoma, epidermal growth factor receptor (HER1), immunohistochemistry, myoepithelial, sarcomatoid carcinoma

Abbreviations: CK, cytokeratin; EGFR, epidermal growth factor receptor; ER, oestrogen receptor; MBC, metaplastic breast carcinoma; PR, progesterone receptor

\section{Introduction}

cDNA microarray studies are reshaping breast cancer taxonomy. It has been demonstrated that breast cancers can be classified according to their gene

\footnotetext{
Address for correspondence: Jorge S Reis-Filho, The Breakthrough Toby Robins Breast Cancer Research Centre, Institute of Cancer Research, Fulham Road, London SW3 6JB, UK.

e-mail: jorgerf@icr.ac.uk

(c) 2006 The Authors. Journal compilation @ 2006 Blackwell Publishing Limited.
}

expression profiles into four main groups: basal-like, luminal (A and B), HER2+ and normal breast-like breast carcinomas. ${ }^{1-6}$ Most importantly, these groups have prognostic and predictive implications. ${ }^{1-3,5-8}$ Tumours classified into the basal-like and HER 2 groups are reported to have a more aggressive clinical behaviour when compared with carcinomas with luminal and normal breast-like phenotypes. ${ }^{1-3,5,6}$

Recently, Nielsen et $a .^{5}$ proposed an immunohistochemical panel, comprising oestrogen receptor (ER), 
Table 1. Immunohistochemical panel for breast cancer classification as defined by Nielsen et al.

\begin{tabular}{llll}
\hline Group & HER2 & ER & $\begin{array}{l}\text { CK5/6 } \\
\text { and/or EGFR }\end{array}$ \\
\hline HER2 & + & Any & Any \\
\hline Luminal & - & + & Any \\
\hline Basal-like & - & - & + \\
\hline Undetermined & - & - & - \\
\hline
\end{tabular}

CK, Cytokeratin; EGFR, epidermal growth factor receptor; $E R$, oestrogen receptor.

epidermal growth factor receptor (EGFR), HER2 and cytokeratin (CK) $5 / 6$, which could be used to identify breast carcinomas with a basal-like phenotype as defined by cDNA microarrays (Table 1). Out of 21 basal-like breast carcinomas by cDNA profiling, 16 were ER- and HER2- and EGFR+ and/or CK5/6+, conferring a sensitivity of $76 \%$ and a specificity of $100 \% .^{5}$

In a preliminary study to characterize the morphological features of basal-like breast carcinomas, ${ }^{9}$ we observed that areas of focal metaplastic change in grade III invasive ductal carcinomas, in the form of spindle and squamous cells, were independent predictors of a basal-like phenotype.

Metaplastic breast carcinoma (MBC) is a descriptive term that refers to a heterogeneous group of tumours characterized by an intimate admixture of adenocarcinoma (i.e. usual types of breast cancer) with metaplastic elements, which can be homologous (squamous or spindle metaplasia) or heterologous (chondroid, osseous or lipomatous differentiation). ${ }^{10-16}$ These tumours account for $<1-3.7 \%$ of all breast carcinomas, depending on the definition and the type of metaplasia. ${ }^{10-16}$ Based upon the immunohistochemical profile and ultrastructural features of MBCs, we $^{17-20}$ and others ${ }^{10,12,21-23}$ have suggested that these tumours show features of myoepithelial differentiation. However, to the best of our knowledge, a systematic assessment of a large series of MBCs encompassing tumours with homologous and heterologous elements, with the immunohistochemical panel designed to identify basal-like carcinomas, has never been performed. Here we report an analysis of a large series of MBCs for the expression of ER, HER 2, EGFR and CK5/6. In addition, we also analysed the distribution of progesterone receptor (PR) and two other basal/myoepithelial markers (CK14 and p63) in these neoplasms.

\section{Materials and methods}

\section{CASE SELECTION}

Cases of MBC were retrieved from the pathology files of The Royal Marsden Hospital (London, UK), The Norwegian Radium Hospital (Montebello, Norway), Institute of Molecular Pathology and Immunology, University of Porto (Porto, Portugal) (IPATIMUP) and Laboratório Salomão \& Zoppi (São Paulo, Brazil). This project was approved by the Local Ethics Committees.

All cases were initially reviewed by the contributing authors, who performed additional immunohistochemical markers for corroborating the diagnosis.

The cases were centrally reviewed by three of the authors (J.S.R-F., F.M. and F.C.S.) on a multiheaded microscope and classified into four categories according to the criteria proposed by Huvos et al. ${ }^{15}$ and Wargotz and Norris. ${ }^{10-14}$ Briefly, tumours were classified as matrix producing breast carcinomas if chondroid and/or osseous matrix was observed in the absence of spindle and osteoclast, i.e. giant cell components. ${ }^{12}$ Neoplasms were classified as spindle cell carcinomas if intraductal or infiltrating ductal or squamous carcinoma of ductal origin was contiguous to or subtly merged with a spindle cell proliferation of neoplastic cells, which comprised at least $50 \%$ of the tumour bulk. ${ }^{10}$ Carcinomas with heterologous elements were defined as tumours with an intraductal or invasive carcinatomous component intimately admixed or subtly merging with a sarcomatous spindle cell component with evidence of chondroid, osseous or rhabdomyoid differentiation. ${ }^{11,15,16}$ Carcinomas with squamous differentiation were predominantly (> 50\%) or completely composed of apparent squamous cell components admixed with areas of invasive ductal and/or spindle cell carcinoma, in the absence of involvement of the overlying skin. ${ }^{14,16} \mathrm{~A}$ median of two representative blocks from each case were selected for immunohistochemical and chromogenic in situ hybridization analysis.

\section{IMMUNOHISTOCHEMISTRY}

Routinely fixed and processed, paraffin-embedded representative tissue sections ( $4 \mu \mathrm{m}$ thick) of each case were cut and mounted on silane-coated slides. Immunohistochemistry with antibodies for ER, PR, EGFR, HER2, CK5/6, CK14 and p63 was performed according to the streptavidin-biotin-peroxidase complex or EnVision ${ }^{\circledR}$ (DakoCytomation) methods as described elsewhere. ${ }^{24}$ Clone details and antigen retrieval methods are summarized in Table 2. Detection was 
Table 2. Antibodies and antigen retrieval methods

\begin{tabular}{lllll}
\hline Antibody & Source & Clone & Dilution & Antigen retriveal \\
\hline HER2 & Dakocytomation, Glostrup, Denmark & $\begin{array}{l}\text { Polyclonal } \\
\text { (Herceptest) }\end{array}$ & Prediluted & 41 min, water bath \\
\hline EGFR & Zymed, South San Francisco, CA, USA & $31 G 7$ & $1: 50$ & 10 min, protease \\
\hline ER & Dakocytomation, Glostrup, Denmark & ID5 & $1: 40$ & 2 min, pressure cooker \\
\hline CK5/6 & Chemicon, Temecula, CA, USA & D516B4 & $1: 600$ & 18 min, microwave oven \\
\hline CK14 & Novocastra, Newcastle-upon-Tyne, UK & LL02 & $1: 40$ & 18 min, microwave oven \\
\hline p63 & Santa Cruz Biotechnology, Santa Cruz, CA, USA & 4A4 & $1: 200$ & 18 min, microwave oven \\
\hline PR & Dakocytomation, Glostrup, Denmark & PGR636 & $1: 150$ & 2 min, pressure cooker \\
\hline
\end{tabular}

CK, Cytokeratin; EGFR, epidermal growth factor receptor; ER, oestrogen receptor; PR, progesterone receptor.

performed with diaminobenzidine chromogen as per routine protocol. ${ }^{24}$ Appropriate positive and negative (omission of the primary antibody and substitution of the primary antibody by non-immune immunoglobulin) controls were included in each slide run. Moreover, internal positive controls were available in the vast majority of the cases (i.e. ER and PR, luminal cells of adjacent ducts and acini; EGFR, CK14, CK5/6 and p63, normal myoepithelial cells of adjacent ducts and acini).

Staining results were assessed by three of the authors (J.S.R-F., F.M., F.S.C.) on a multihead microscope. A threshold of $\geq 10 \%$ of positive neoplastic cells was adopted for ER, CK5/6, CK14 and PR. EGFR and HER2 were scored according to the guidelines for Herceptest ${ }^{\circledR} \cdot{ }^{25}$ Only nuclear staining was considered positive for ER, PR and p63, whereas only cytoplasmic staining was considered positive for CK5/6 and CK14. Membranous staining with or without cytoplasmic staining was regarded as specific for EGFR and HER2. A case was considered positive for a given marker only when all observers agreed upon its specificity and distribution.

\section{Results}

The histological classification and immunohistochemical results are summarized in Table 3.

\section{HER 2}

All but two MBCs lacked HER2 overexpression $(2+$ or $3+)$. Both were carcinomas with squamous metaplasia. Case 14, which showed HER2 2+, was subjected to chromogenic in situ hybridization for HER2, which demonstrated lack of amplification of HER2 gene (data not shown). Therefore, this case was considered negative.

\section{OESTROGEN RECEPTOR}

One spindle cell carcinoma and one carcinoma with squamous metaplasia were positive for ER. Interestingly, in case 46 , the metaplastic spindle cells were positive for ER, whereas in case 12 only the invasive ductal component was ER+, whereas the metaplastic squamous cells were consistently negative.

\section{EPIDERMAL GROWTH FACTOR RECEPTOR}

EGFR overexpression, defined as $2+$ and $3+$ reactivity, was observed in $37 / 65(56.9 \%)$ of all MBCs, including $12 / 21(57.1 \%)$ spindle cell carcinomas, $14 / 19(73.7 \%)$ carcinomas with squamous metaplasia, 5/18 (27.8\%) matrix producing breast carcinomas and $5 / 7(71.4 \%)$ carcinomas with heterologous elements.

CK $5 / 6$

Fifty-six of 65 (86.1\%) MBCs were positive for CK5/6. Five spindle cell carcinomas, two matrix producing breast carcinomas and two carcinomas with heterologous elements lacked CK5/6 expression.

\section{CK 14}

Fifty-three of 65 (81.5\%) MBCs displayed CK14 positivity. Five spindle cell carcinomas, four matrix producing breast carcinomas, two carcinomas with squamous metaplasia and two carcinomas with heterologous elements lacked CK14 expression.

Interestingly, three cases of spindle cell carcinoma, one matrix producing carcinoma and one carcinoma with heterologous elements lacked both CK5/6 
Table 3. Summary of immunohistochemical findings

\begin{tabular}{|c|c|c|c|c|c|c|c|c|}
\hline Case & Diagnosis & Her2 & ER & EGFR & CK5/6 & CK14 & p63 & PR \\
\hline 1 & Carcinoma with heterologous elements & - & - & - & + & - & + & + \\
\hline 2 & Carcinoma with heterologous elements & - & - & $1+$ & + & + & + & - \\
\hline 3 & Carcinoma with heterologous elements & - & - & $2+$ & - & + & + & - \\
\hline 4 & Carcinoma with heterologous elements & - & - & $2+$ & + & + & + & - \\
\hline 5 & Carcinoma with heterologous elements & - & - & $3+$ & - & - & + & - \\
\hline 6 & Carcinoma with heterologous elements & - & - & $3+$ & + & + & + & - \\
\hline 7 & Carcinoma with heterologous elements & - & - & $3+$ & + & + & + & - \\
\hline 8 & Carcinoma with squamous metaplasia & - & - & - & + & + & + & + \\
\hline 9 & Carcinoma with squamous metaplasia & - & - & - & + & + & - & + \\
\hline 10 & Carcinoma with squamous metaplasia & - & - & $1+$ & + & + & - & - \\
\hline 11 & Carcinoma with squamous metaplasia & $1+$ & - & $1+$ & + & + & - & - \\
\hline 12 & Carcinoma with squamous metaplasia & - & + & $1+$ & + & + & + & + \\
\hline 13 & Carcinoma with squamous metaplasia & - & - & $2+$ & + & - & + & - \\
\hline 14 & Carcinoma with squamous metaplasia & $2+$ & - & $3+$ & + & + & + & - \\
\hline 15 & Carcinoma with squamous metaplasia & - & - & $3+$ & + & + & + & - \\
\hline 16 & Carcinoma with squamous metaplasia & - & - & $3+$ & + & + & + & - \\
\hline 17 & Carcinoma with squamous metaplasia & - & - & $3+$ & + & + & + & - \\
\hline 18 & Carcinoma with squamous metaplasia & - & - & $3+$ & + & + & + & - \\
\hline 19 & Carcinoma with squamous metaplasia & - & - & $3+$ & + & + & + & - \\
\hline 20 & Carcinoma with squamous metaplasia & - & - & $3+$ & + & + & + & - \\
\hline 21 & Carcinoma with squamous metaplasia & - & - & $3+$ & + & + & + & - \\
\hline 22 & Carcinoma with squamous metaplasia & - & - & $3+$ & + & + & + & - \\
\hline 23 & Carcinoma with squamous metaplasia & - & - & $3+$ & + & + & + & - \\
\hline 24 & Carcinoma with squamous metaplasia & - & - & $3+$ & + & + & - & - \\
\hline 25 & Carcinoma with squamous metaplasia & $3+$ & - & $3+$ & + & + & + & - \\
\hline 26 & Carcinoma with squamous metaplasia & - & - & $3+$ & + & - & + & + \\
\hline 27 & Matrix producing carcinoma & - & - & - & - & + & + & - \\
\hline 28 & Matrix producing carcinoma & - & - & - & + & + & + & - \\
\hline 29 & Matrix producing carcinoma & - & - & - & + & + & + & - \\
\hline 30 & Matrix producing carcinoma & - & - & - & + & + & + & - \\
\hline 31 & Matrix producing carcinoma & - & - & - & + & + & - & - \\
\hline
\end{tabular}


$14 J$ S Reis-Filho et al.

Table 3. (Continued)

\begin{tabular}{|c|c|c|c|c|c|c|c|c|}
\hline Case & Diagnosis & Her2 & ER & EGFR & $\mathrm{CK} 5 / 6$ & CK14 & p63 & PR \\
\hline 32 & Matrix producing carcinoma & - & - & - & + & + & - & - \\
\hline 33 & Matrix producing carcinoma & - & - & - & + & + & - & - \\
\hline 34 & Matrix producing carcinoma & - & - & - & + & + & - & - \\
\hline 35 & Matrix producing carcinoma & - & - & - & + & + & - & - \\
\hline 36 & Matrix producing carcinoma & - & - & $1+$ & - & - & - & - \\
\hline 37 & Matrix producing carcinoma & - & - & $1+$ & + & - & + & - \\
\hline 38 & Matrix producing carcinoma & - & - & $1+$ & + & + & + & - \\
\hline 39 & Matrix producing carcinoma & - & - & $1+$ & + & + & - & - \\
\hline 40 & Matrix producing carcinoma & - & - & $2+$ & + & + & + & - \\
\hline 41 & Matrix producing carcinoma & - & - & $2+$ & + & + & + & - \\
\hline 42 & Matrix producing carcinoma & - & - & $3+$ & + & - & + & - \\
\hline 43 & Matrix producing carcinoma & - & - & $3+$ & + & + & + & - \\
\hline 44 & Matrix producing carcinoma & - & - & $3+$ & + & + & + & - \\
\hline 45 & Spindle cell carcinoma & - & - & - & - & + & - & - \\
\hline 46 & Spindle cell carcinoma & - & + & - & - & - & + & - \\
\hline 47 & Spindle cell carcinoma & - & - & - & + & + & + & - \\
\hline 48 & Spindle cell carcinoma & - & - & - & + & + & + & - \\
\hline 49 & Spindle cell carcinoma & - & - & - & + & + & + & - \\
\hline 50 & Spindle cell carcinoma & - & - & - & + & + & + & - \\
\hline 51 & Spindle cell carcinoma & - & - & - & + & + & + & - \\
\hline 52 & Spindle cell carcinoma & - & - & $1+$ & + & + & + & - \\
\hline 53 & Spindle cell carcinoma & - & - & $1+$ & + & + & + & - \\
\hline 54 & Spindle cell carcinoma & - & - & $2+$ & - & - & + & - \\
\hline 55 & Spindle cell carcinoma & - & - & $2+$ & - & - & + & - \\
\hline 56 & Spindle cell carcinoma & - & - & $2+$ & + & + & + & - \\
\hline 57 & Spindle cell carcinoma & - & - & $3+$ & - & - & + & - \\
\hline 58 & Spindle cell carcinoma & - & - & $3+$ & + & - & - & - \\
\hline 59 & Spindle cell carcinoma & - & - & $3+$ & + & + & + & - \\
\hline 60 & Spindle cell carcinoma & - & - & $3+$ & + & + & + & - \\
\hline 61 & Spindle cell carcinoma & - & - & $3+$ & + & + & + & - \\
\hline 62 & Spindle cell carcinoma & - & - & $3+$ & + & + & + & - \\
\hline
\end{tabular}


Table 3. (Continued)

\begin{tabular}{lllllllll}
\hline Case & Diagnosis & Her2 & ER & EGFR & CK5/6 & CK14 & P63 & PR \\
\hline 63 & Spindle cell carcinoma & - & - & $3+$ & + & + & + \\
\hline 64 & Spindle cell carcinoma & - & - & $3+$ & + & + & + \\
\hline 65 & Spindle cell carcinoma & - & - & $3+$ & + & + & + \\
\hline
\end{tabular}

CK, Cytokeratin; EGFR, epidermal growth factor receptor; ER, oestrogen receptor; $\mathrm{PR}$, progesterone receptor.

and CK14 expression. However, these cases either expressed other keratins (CK8/18, CK19 or 34ßE12, data not shown) and/or were associated with highgrade ductal carcinoma in situ.

p 63

Fifty-two out of $65(80 \%)$ MBCs showed p63 expression. In seven matrix producing breast carcinomas, four carcinomas with squamous metaplasia and two spindle cell carcinomas $<10 \%$ of p $63+$ neoplastic cells were identified, rendering these cases negative. Interestingly, all but one of the cases that lacked both CK5/6 and CK14 were positive for p63. This case was a matrix producing breast carcinoma which showed positivity for CK8/18 and CK19.

\section{PROGESTERONE RECEPTOR}

Four of $19(21.0 \%)$ carcinomas with squamous metaplasia and one of seven $(14.3 \%)$ carcinomas with heterologous elements expressed PR, which was largely restricted to areas with squamous metaplasia. Interestingly, in cases 8 and 26, PR decorated only the nonmetaplastic elements. The remaining cases consistently lacked PR expression.

\section{CLASSIFICATION OF METAPLASTIC BREAST CANCER} INTO HER 2, LUMINAL AND BASAL-LIKE GROUPS

Following the immunohistochemical panel proposed by Nielsen et al., 59 out of 65 MBCs (90.8\%) displayed the typical immunophenotype of basal-like breast carcinomas (Table 4 and Figures 1, 2 and 3). Three cases, two matrix producing breast carcinomas (cases 27 and 36) and one spindle cell carcinoma (case 45), were negative for ER and HER2, but also lacked EGFR and CK5/6 expression.

Two cases showed the immunophenotype of luminal tumours (one carcinoma with squamous metaplasia and one spindle cell carcinoma) and another case of carcinoma with squamous metaplasia was classified into the HER2 group. Interestingly, all of these cases expressed at least one basal/myoepithelial marker.

Furthermore, one matrix producing breast carcinoma (case 27) and one spindle cell carcinoma (case 45) that were both HER2-, ER-, CK5/6- and EGFR- were positive for p63 and/or CK14. Hence, these cases could be considered of basal-like phenotype if these antibodies were included in the immunohistochemical panel for identifying basal-like tumours.

\section{Discussion}

We have demonstrated that $90.8 \%$ of MBCs show a basal-like immunophenotype as defined by Nielsen et al. ${ }^{5}$ By including p63 and CK14 in the immunohistochemical panel, 61 out 65 (93.8\%) MBCs were classified as basal-like tumours.

In previous studies addressing clinicopathological characteristics of basal-like carcinomas, it has been reported that these tumours are usually of high grade, lack well-formed ductal structures, harbour high proliferation rates, have centrally necrotic/sclerotic zones and show a proclivity to disseminate to the brain and lungs, sparing regional nodes, liver and
Table 4. Classification of 65 metaplastic breast carcinomas according to the immunohistochemilcal panel proposed by Nielsen et al.

\begin{tabular}{lccccc}
\hline Histological type & $N$ & HER2 & Luminal & Basal-like & Undetermined \\
\hline Spindle cell carcinoma & 21 & 0 & 1 & 19 & 1 \\
\hline Carcinoma with squamous metaplasia & 19 & 1 & 1 & 17 & 0 \\
\hline Matrix producing breast carcinoma & 18 & 0 & 0 & 16 & 2 \\
\hline Carcinoma with heterologous elements & 7 & 0 & 0 & 7 & 0 \\
\hline
\end{tabular}



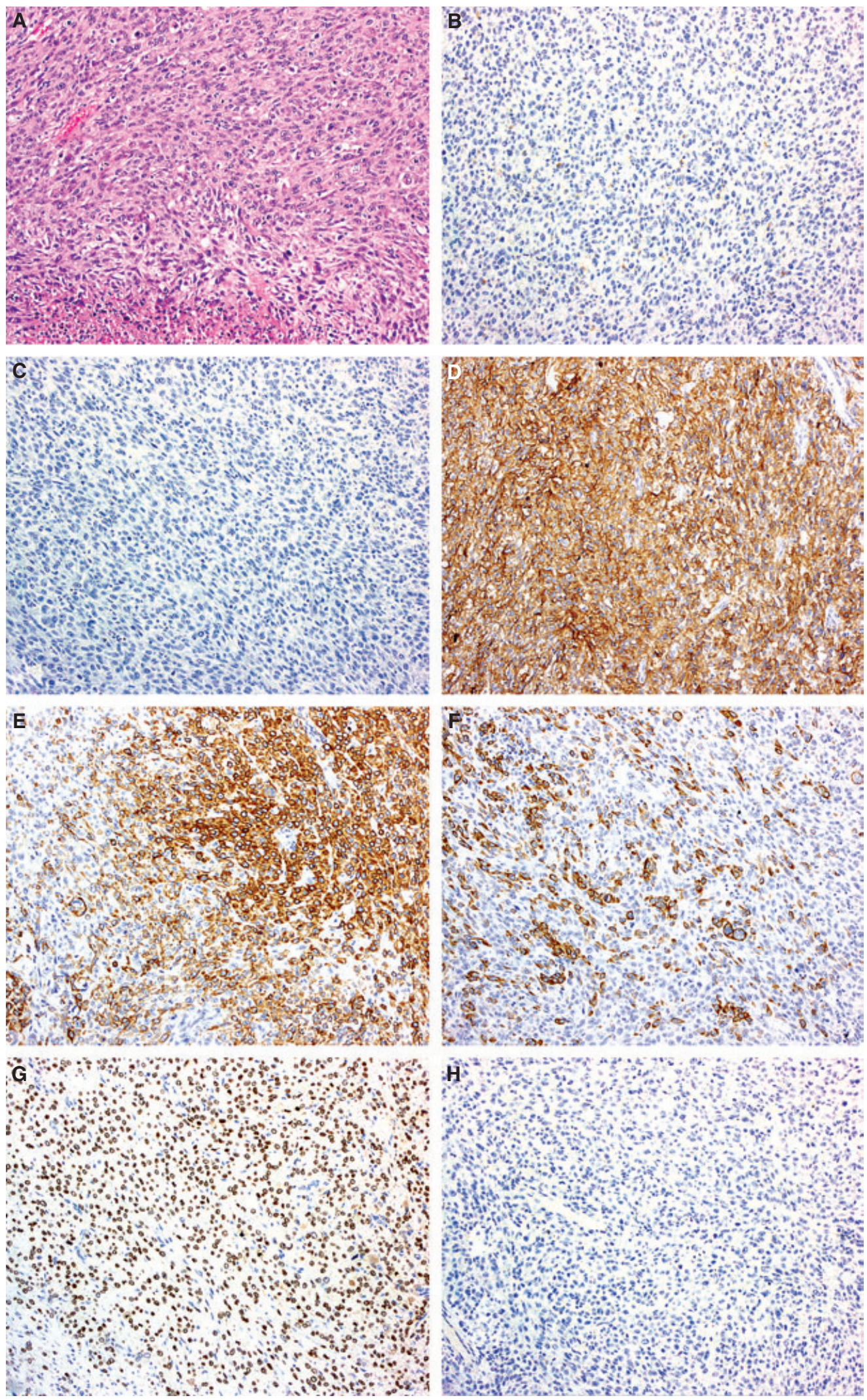

Figure 1. Spindle cell carcinoma (case 63): A, H\&E; B, HER2; C, ER; D, EGFR; E, CK5 / 6; F, CK14; G, p63; H, PR. 

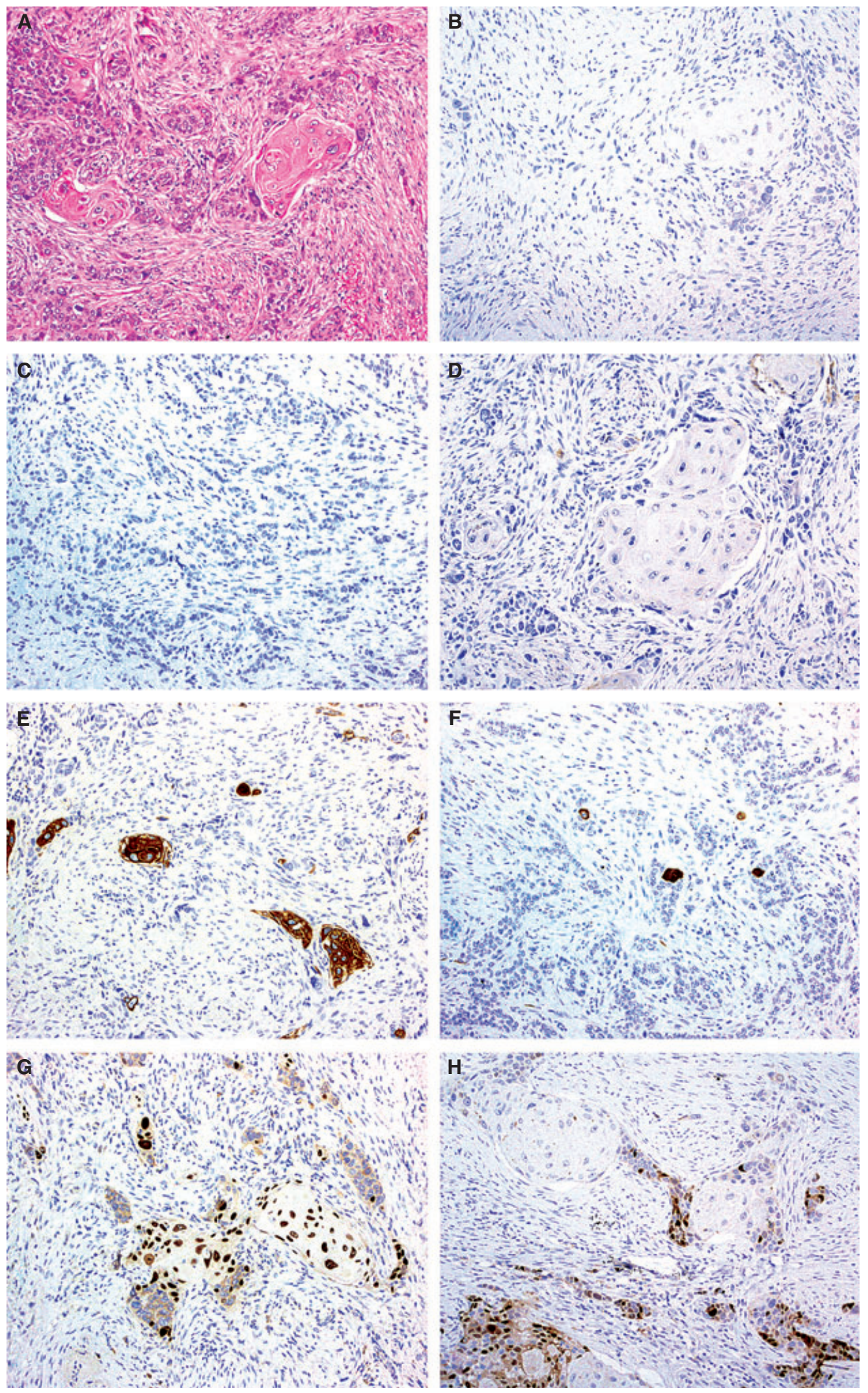

Figure 2. Carcinoma with squamous metaplasia (case 8): A, H\&E; B, HER2; C, ER; D, EGFR; E, CK5/6; F, CK14; G, p63; H, PR. 

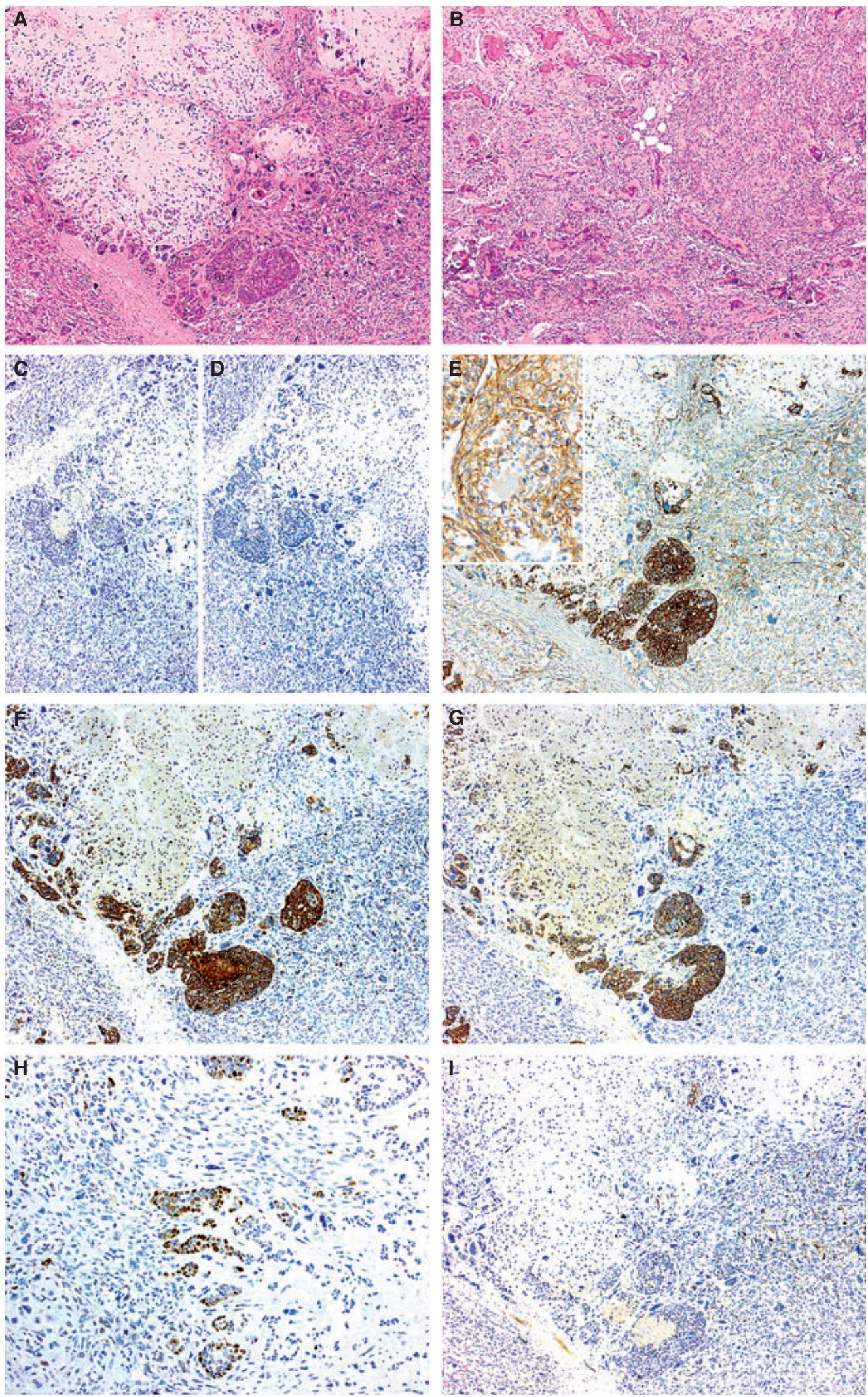

Figure 3. Carcinoma with heterologous elements (case 7): A,B, H\&E; C, HER2; D, ER; E, EGFR, inset EGFR; F, CK5/6; G, CK14; H, p63; I, PR. 
bone. $^{7,26-28}$ Recently, Jacquemier et al. demonstrated that medullary carcinomas also show a basal-like immunophenotype. ${ }^{29}$ Our results suggest that the spectrum of basal-like breast carcinomas is wider than previously appreciated and that metaplastic elements are also features of basal-like breast cancers.

We and others have demonstrated that matrix producing breast carcinomas, spindle cell carcinomas and carcinomas with heterologous elements consistently show features of basal/myoepithelial differentiation. ${ }^{10,12,17-19,21,22,30,31}$ It has been suggested that breast carcinomas with squamous metaplasia should not be considered within the category of tumours with myoepithelial differentiation. ${ }^{23}$ Although these tumours consistently express basal markers (CK5/6, Ck14 and p63), ${ }^{18,19,23,32}$ expression of myoid markers is usually not found. ${ }^{19,23}$ However, there are several lines of evidence to suggest that carcinomas with squamous metaplasia should also be considered part of the spectrum of tumours with basal/myoepithelial differentiation: (i) Raju ${ }^{33}$ and Reddick et al. ${ }^{34}$ have demonstrated a transition between myoepithelial cells and squamous cells in benign breast lesions at histological, immunohistochemical and ultrastructural levels; (ii) sorted breast myoepithelial cells, and not breast luminal cells, undergo squamous metaplasia when cultured in specific media; ${ }^{35}$ (iii) foci of squamous metaplasia are frequently found in spindle cell carcinomas and spindle cell metaplasia is not rare in breast carcinomas with squamous metaplasia; ${ }^{10,11,16,31,36,37}$ and (iv) matrix producing breast carcinomas and carcinomas with heterologous elements frequently harbour foci of squamous differentiation. ${ }^{12}$ Therefore, the classification proposed by Leibl et al. ${ }^{23}$ in which MBCs are grouped into (i) MBCs with squamous differentiation and (ii) $\mathrm{MBCs}$ with a myoepithelial immunophenotype seems to be artificial and unjustified.

The fact that up to $93.8 \%$ of all MBCs display a basallike phenotype has a significant impact on our understanding of the biology and management of patients diagnosed with these lesions. Basal-like breast carcinomas are reported to have a more aggressive clinical behaviour and a less significant response to anthracycline-based adjuvant chemotherapy than luminal and normal-like breast carcinomas. ${ }^{37 a}$ Furthermore, Rouzier et al. ${ }^{38}$ have recently demonstrated that up to $45 \%$ of basal-like breast carcinomas show a pathological complete response after 12 weeks of paclitaxel followed by four courses of neoadjuvant chemotherapy with 5-fluorouracil, doxorubicin and cyclophosphamide. ${ }^{38}$

A surprising finding in this study is that $7.7 \%$ of MBCs showed expression of PR. Interestingly, PR positivity was almost restricted to the metaplastic squamous cells of the carcinoma with heterologous elements and the four carcinomas with squamous metaplasia. However, PR is not part of the 'intrinsic gene list' used in cDNA microarray studies to classify breast carcinomas into the five main groups. ${ }^{2-4,38}$ Although PR expression per se would not render the classification of these tumours as basal-like invalid, it suggests that basal-like carcinomas are not homogeneous. In fact, there are several lines of evidence to suggest that basal-like carcinomas are not homogeneous in terms of their expression profiles ${ }^{6,8,29,39}$ and molecular genetic features. ${ }^{40}$

Unlike the majority of invasive ductal breast carcinomas, MBCs are unlikely to respond to conventional hormone therapy and anti-Her2 therapeutic schemes, as these lesions consistently lack ER expression and HER2 overexpression/gene amplification. ${ }^{41-43}$ In a recent study, our group has shown that up to $25 \%$ of MBCs harbour EGFR gene amplifications. ${ }^{41}$ Given that there are compelling data to suggest that tumours harbouring EGFR amplification may respond to EGFR inhibitors, ${ }^{44}$ studies addressing the efficacy of these agents for the treatment of patients with MBCs are warranted.

\section{Acknowledgements}

This study was funded by Breakthrough Breast Cancer. J.S.R-F. is supported in part by a $\mathrm{PhD}$ grant reference SFRH/BD/5386/2001 from the Fundação para a Ciência e a Tecnologia, Portugal. F.C.S. is the principal investigator of the grant POCTI/CBO/45157/2002 from Programa Operacional Ciência, Tecnologia e Inovação, Fundação para a Ciência e a Tecnologia, Portugal. The authors thank Professor M. F. Franco for his invaluable comments.

\section{References}

1. van de Rijn M, Perou CM, Tibshirani R et al. Expression of cytokeratins 17 and 5 identifies a group of breast carcinomas with poor clinical outcome. Am. J. Pathol. 2002; 161; 19911996.

2. Sorlie T, Tibshirani R, Parker J et al. Repeated observation of breast tumor subtypes in independent gene expression data sets. Proc. Natl Acad. Sci. USA 2003; 100; 8418-8423.

3. Sorlie T, Perou CM, Tibshirani $\mathrm{R}$ et al. Gene expression patterns of breast carcinomas distinguish tumor subclasses with clinical implications. Proc. Natl Acad. Sci. USA 2001; 98; 10869-10874.

4. Perou CM, Sorlie T, Eisen MB et al. Molecular portraits of human breast tumours. Nature 2000; 406; 747-752.

5. Nielsen TO, Hsu FD, Jensen $\mathrm{K}$ et al. Immunohistochemical and clinical characterization of the basal-like subtype of 
invasive breast carcinoma. Clin. Cancer Res. 2004; 10; 53675374.

6. Sotiriou C, Neo SY, McShane LM et al. Breast cancer classification and prognosis based on gene expression profiles from a population-based study. Proc. Natl Acad. Sci. USA 2003; 100; 10393-10398.

7. Abd El-Rehim DM, Pinder SE, Paish CE et al. Expression of luminal and basal cytokeratins in human breast carcinoma. J. Pathol. 2004; 203; 661-671.

8. Abd El-Rehim DM, Ball G, Pinder SE et al. High-throughput protein expression analysis using tissue microarray technology of a large well-characterised series identifies biologically distinct classes of breast cancer confirming recent cDNA expression analyses. Int. J. Cancer 2005; 116; 340-350.

9. Fulford LG, Easton DF, Sofronis A et al. Specific morphological features predictive for the basal phenotype in grade 3 invasive ductal carcinomas of the breast. Pathol. Int. 2004; 54; A2-A3 [Abstract].

10. Wargotz ES, Deos PH, Norris HJ. Metaplastic carcinomas of the breast. II. Spindle cell carcinoma. Hum. Pathol. 1989; 20; 732-740.

11. Wargotz ES, Norris HJ. Metaplastic carcinomas of the breast. III. Carcinosarcoma. Cancer 1989; 64; 1490-1499.

12. Wargotz ES, Norris HJ. Metaplastic carcinomas of the breast. I. Matrix-producing carcinoma. Hum. Pathol. 1989; 20; 628635.

13. Wargotz ES, Norris HJ. Metaplastic carcinomas of the breast. V. Metaplastic carcinoma with osteoclastic giant cells. Hum. Pathol. 1990; 21; 1142-1150.

14. Wargotz ES, Norris HJ. Metaplastic carcinomas of the breast. IV. Squamous cell carcinoma of ductal origin. Cancer 1990; 65; 272-276.

15. Huvos AG, Lucas JC Jr, Foote FW Jr. Metaplastic breast carcinoma. Rare form of mammary cancer. NY State J. Med. 1973; 73; 1078-1082.

16. Oberman HA. Metaplastic carcinoma of the breast. A clinicopathologic study of 29 patients. Am. J. Surg. Pathol. 1987; 11; 918-929.

17. Reis-Filho JS, Milanezi F, Silva P, Schmitt FC. Maspin expression in myoepithelial tumors of the breast. Pathol. Res. Pract. 2001; $197 ; 817-821$.

18. Reis-Filho JS, Schmitt FC. p63 expression in sarcomatoid/metaplastic carcinomas of the breast. Histopathology 2003; 42; 94-95.

19. Reis-Filho JS, Milanezi F, Paredes J et al. Novel and classic myoepithelial/stem cell markers in metaplastic carcinomas of the breast. Appl. Immunohistochem. Mol. Morph. 2003; 11; $1-8$.

20. Simpson PT, Gale T, Reis-Filho JS et al. Distribution and significance of 14-3-3sigma, a novel myoepithelial marker, in normal, benign, and malignant breast tissue. J. Pathol. 2004; 202; 274-285.

21. Popnikolov NK, Ayala AG, Graves K, Gatalica Z. Benign myoepithelial tumors of the breast have immunophenotypic characteristics similar to metaplastic matrix-producing and spindle cell carcinomas. Am. J. Clin. Pathol. 2003; 120; 161167.

22. Dunne B, Lee AH, Pinder SE, Bell JA, Ellis IO. An immunohistochemical study of metaplastic spindle cell carcinoma, phyllodes tumor and fibromatosis of the breast. Hum. Pathol. 2003; 34; 1009-1015.

23. Leibl S, Gogg-Kammerer M, Sommersacher A, Denk H, Moinfar F. Metaplastic breast carcinomas: are they of myoepithelial differentiation?: immunohistochemical profile of the sarcomatoid subtype using novel myoepithelial markers. Am. J. Surg. Pathol. 2005; 29; 347-353.

24. Reis-Filho JS, Simpson PT, Jones C et al. Pleomorphic lobular carcinoma of the breast: role of comprehensive molecular pathology in characterization of an entity. J. Pathol. 2005; 207; 1-13.

25. Jacobs TW, Gown AM, Yaziji H, Barnes MJ, Schnitt SJ. Specificity of HercepTest in determining HER-2/neu status of breast cancers using the United States Food and Drug Administration-approved scoring system. J. Clin. Oncol. 1999; 17; 1983-1987.

26. Lakhani SR, Reis-Filho JS, Fulford L et al. Prediction of BRCA1 status in patients with breast cancer using estrogen receptor and basal phenotype. Clin. Cancer Res. 2005; 11; 5175-5180.

27. Tsuda H, Takarabe T, Hasegawa F, Fukutomi T, Hirohashi S. Large, central acellular zones indicating myoepithelial tumor differentiation in high-grade invasive ductal carcinomas as markers of predisposition to lung and brain metastases. Am. J. Surg. Pathol. 2000; 24; 197-202.

28. Tsuda H, Takarabe T, Hasegawa T, Murata T, Hirohashi S. Myoepithelial differentiation in high-grade invasive ductal carcinomas with large central acellular zones. Hum. Pathol. 1999; 30; $1134-1139$

29. Jacquemier J, Padovani L, Rabayrol L et al. Typical medullary breast carcinomas have a basal/myoepithelial phenotype. J. Pathol. 2005; 207; 260-268.

30. Sapino A, Papotti M, Sanfilippo B, Gugliotta P, Bussolati G. Tumor types derived from epithelial and myoepithelial cell lines of R3230AC rat mammary carcinoma. Cancer Res. 1992; 52; $1553-1560$

31. Koker MM, Kleer CG. p63 expression in breast cancer: a highly sensitive and specific marker of metaplastic carcinoma. Am. J. Surg. Pathol. 2004; 28; 1506-1512.

32. Adem C, Reynolds C, Adlakha H, Roche PC, Nascimento AG. Wide spectrum screening keratin as a marker of metaplastic spindle cell carcinoma of the breast: an immunohistochemical study of 24 patients. Histopathology 2002; 40; 556-562.

33. Raju GC. The histological and immunohistochemical evidence of squamous metaplasia from the myoepithelial cells in the breast. Histopathology 1990; 17; 272-275.

34. Reddick RL, Jennette JC, Askin FB. Squamous metaplasia of the breast. An ultrastructural and immunologic evaluation. Am. J. Clin. Pathol. 1985; 84; 530-533.

35. O'Hare MJ, Ormerod MG, Monaghan P, Lane EB, Gusterson BA. Characterization in vitro of luminal and myoepithelial cells isolated from the human mammary gland by cell sorting. Differentiation 1991; 46; 209-221.

36. Enghardt MH, Hale JH. An epithelial and spindle cell breast tumour of myoepithelial origin. An immunohistochemical and ultrastructural study. Virchows Arch. A Pathol. Anat. Histopathol. 1989; 416; 177-184.

37. Harb JM, Komorowski RA, Vitali CM. Metaplastic breast carcinoma invading chest wall. Ultrastruct. Pathol. 1995; 19; 439-443.

37a. Banerjee S, Reis-Filho JS, Ashley S et al. Basal-like breast carcinomas: clinical outcome and response to chemotherapy. J. Clin. Pathol. 2006; DOI: 10.1136/jcp.2005.033043.

38. Rouzier R, Perou CM, Symmans WF et al. Breast cancer molecular subtypes respond differently to preoperative chemotherapy. Clin. Cancer Res. 2005; 11; 5678-5685.

39. Matos I, Dufloth R, Alvarenga M, Zeferino LC, Schmitt F. p63, cytokeratin 5, and P-cadherin: three molecular markers to 
distinguish basal phenotype in breast carcinomas. Virchows Arch. 2005; 447; 688-694.

40. Jones C, Ford E, Gillett C et al. Molecular cytogenetic identification of subgroups of grade III invasive ductal breast carcinomas with different clinical outcomes. Clin. Cancer Res. 2004; 10; 5988-5997.

41. Reis-Filho JS, Milanezi F, Carvalho S et al. Metaplastic breast carcinomas show EGFR, but not HER2, gene amplification and overexpression: immunohistochemical and chromogenic in situ hybridisation analysis. Breast Cancer Res. 2005; 7; R1028-1035.
42. Leibl S, Moinfar F. Metaplastic breast carcinomas are negative for Her-2 but frequently express EGFR (Her-1): potential relevance to adjuvant treatment with EGFR tyrosine kinase inhibitors? J. Clin. Pathol. 2005; 58; 700-704.

43. Barnes PJ, Boutilier R, Chiasson D, Rayson D. Metaplastic breast carcinoma: clinical-pathologic characteristics and HER2/neu expression. Breast Cancer Res. Treat. 2005; 91; 173-178.

44. Cappuzzo F, Hirsch FR, Rossi E et al. Epidermal growth factor receptor gene and protein and gefitinib sensitivity in non-smallcell lung cancer. J. Natl Cancer Inst. 2005; 97; 643-655. 